EDITORIAL

\title{
25 ANOS DE EDUCAÇÃO \& SOCIEDADE: SUA INTERNACIONALIZAÇÃO
}

$\mathcal{E}$

ducação \& Sociedade, em 2003, está completando 25 anos de existência. Sua caminhada inicia-se em tempo histórico marcado pelo processo de redemocratização do país - tempo de muita luta, mas de muita esperança - que ficou inscrito em sua trajetória. Contrariamente à fragmentação, contingência e efemeridade, características dos periódicos científicos de escolas de pensamento com larga repercussão no campo científico da educação nas últimas décadas, a revista quadrimestral de Ciência da Educação, Educação \& Sociedade, teve editado, em setembro de 1978, pela Editora Cortez \& Moraes, seu número um, "O educador precisa ser educado". Editada ininterruptamente, chega hoje, 25 anos passados, a seu $82^{\circ}$ número, Ano 24.

$O$ grupo que teve a iniciativa de criação da $E \mathcal{H} S$ definiu-a como uma

revista preocupada com a análise da realidade educacional brasileira, abrindo seu espaço para propostas intelectuais, tanto no que se refere a técnicas, doutrinas e práticas educacionais, como no que se refere a reflexão sobre seu impacto na sociedade como um todo: uma revista que tenha como foco uma perspectiva da teoria e da prática no âmbito do conhecimento sócio-educativo, procurando recuperar certa informação histórica dessa prática e teoria, sem deixar de responder aos problemas colocados pela educação brasileira contemporânea. (...). (Editorial da revista $\mathrm{n}^{\circ} 1,1978$, p. 3)

A origem da revista foi a Faculdade de Educação da Unicamp e seus organizadores, definindo a sua abrangência, apresenta-a expressando

A comemoração dos 25 anos, quando a revista se encontra em seu volume 24 e não 25 , é resultado do fato de que os números 2,3 e 4 foram editados como sendo do ano 1 .

Educ. Soc., Campinas, vol. 24, n. 82, p. 9-14, abril 2003

Disponível em <http://www.cedes.unicamp.br> 
opiniōes, práticas e produção intelectual de seus docentes e alunos, mas está aberta a outras instituiçôes e pessoas que, em caráter individual, queiram aderir a seu compromisso de reanimar a audiência, o debate e a crítica em torno dos problemas educacionais brasileiros a fim de repensar a educação passo a passo com a construção da sociedade, reconhecendo que é esta a grande tarefa atual das ciências da educação. (Idem, ibid.)

Seus editores expressam em seu compromisso a abrangência nacional da revista, o que veio a ser uma de suas marcas, na trajetória traçada ao longo da sua existência construída na linha da intersecção da educação e sociedade.

Entretanto, os editores revisitam esta abrangência em seu segundo número, janeiro de 1979, quando no Editorial evidenciam um novo horizonte para a revista:

(...) O número de educadores e de instituições que aderiram ao nosso compromisso de reanimar o debate e a crítica da educação no Brasil levou-nos a ampliar nosso quadro de colaboradores, conseqüentemente, o nosso horizonte de trabalho. Por corresponder aos anseios de muitos, não podíamos deixar esse veículo de manifestação do pensamento e de ação ligado apenas a um pequeno grupo, dentro de uma instituição. Por isso, E\&S passa a ser um ponto de integração e de associação de todos os educadores que queiram retomar a educação na perspectiva de suas relações com a sociedade. Esforços no sentido de reuni-los num centro - que provisoriamente chamamos 'Centro de Estudos Educação e Sociedade' (CEDES) - já estão sendo feitos. A consolidação de uma revista em nível nacional - portadora da produção e da reflexão-ação de um grupo numeroso de educadores - deverá prestar um serviço ainda maior para a educação brasileira (...). (1979, p. 3)

A ligação da revista com os movimentos sociais ocorrendo na educação no país é a cunha desse editorial, marcando sua trajetória e reorientando-a na busca de uma estrutura que permitisse sua consolidação, através da criação do CEDES, com a clara intenção não só da ampliação do campo da ação dos educadores, como também de definição do lugar que se pretendia construir como o de articulação desta luta. Muito rapidamente, no dia 5 de março de 1979, aquele grupo, fundador da revista na Faculdade de Educação da UNICAMP, ampliado agora com outros educadores igualmente compromissados com a educação brasileira e com o seu papel político, bem como com a democratização da educação e da sociedade nacionais, cria o CEDES como sociedade civil sem fins lucrativos. Os objetivos definidos para o Centro consolidam e ampliam a ação da revista reforçada pela decisão de retomar-se a orga- 
nização das Conferências Nacionais da Educação, agora na nova série Conferência Brasileira de Educação ( $\mathrm{CBE}$ ), em continuidade ao que deveria ser o II Seminário da Educação Brasileira, cujo tema refletia a luta pela transformação da educação: Políticas Educacionais.

O CEDES, mais duas associações do campo da educação - Associação Nacional de Educação (ANDE) e Associação Nacional de Pós-Graduação em Educação (ANPEd) - e, no início, o Centro de Estudos de Cultura Contemporânea (CEDEC) assumiram a promoção das seis CBEs na década de 1980 e a última em 1991. Ao longo do tempo, o CEDES tem participado de inúmeros movimentos de reorganização e reordenamento da educação nacional, interferindo nas esferas do poder federal, estaduais e municipais. Esteve presente ainda no processo de luta pela Anistia; no Fórum Nacional de Educação, na Constituinte, em defesa da escola pública; e, desde 1989, acompanhando, no Congresso Nacional, a elaboração e tramitação da nova Lei de Diretrizes e Bases da Educação Nacional e as discussões em torno do Plano Nacional de Educação.

Cumprindo seus objetivos iniciais, o CEDES desenvolveu ainda, nos anos de 1990, importante programa integrado de pesquisa, com a participação de pesquisadores de universidades brasileiras sobre "Ciência \& Tecnologia: qualificação e produção", com resultados publicados na revista, na seção "Pesquisa no CEDES".

Educação \& Sociedade participou com muita ênfase da reorganização do campo educacional na década de 1980 e seus números guardam registros de diferentes movimentos da época. Igualmente foi um importante e incansável ator do movimento dos editores. Ao longo de sua trajetória, a política editorial do CEDES para Educação \& Sociedade foi sendo construída alcançando maior explicitação nos últimos anos. Desde 1995, a partir do no 53, a introdução de um número especial temático por ano ("Educação e Democracia: limites impostos pelo autoritarismo social") tornou a revista quadrimestral. Os temas tratados nesses números temáticos foram: "Teorias críticas e liberalismo: contrastes e confrontos" (no 57, 1996); "Tecnologia, trabalho e educação" (no 61, 1997); "Competência, qualificação e trabalho" (no 64, 1998): "Formação de profissionais da educação: políticas e tendências" (no 68, 1999); "Vigotski - O manuscrito de 1929: temas sobre a constituição cultural do homem" (no 71, 2000); "Ética, educação e sociedade: um debate contemporâneo" (no 76, 2001); "Políticas públicas para a educação: olhares diversos sobre o período de 1995 a 2002" (no 80, 2002). Estes números dão visibilidade aos objetivos dessa política, que permite não só retomar, introduzir e aprofundar temas contemporâneos da educação, na sua relação com a sociedade, mas também difundir os conhe- 
cimentos resultantes de pesquisas que vêm sendo produzidas no campo educacional, no Brasil e no exterior.

Resultante dessa política editorial, desde o $\mathrm{n}^{\circ}$ 63, de 1998, foram incluídos Dossiês que abordaram as temáticas "Universidade em tempos difíceis", "Ensino Médio" (no 70, 2000); "Política curriculares e decisões epistemológicas ( $\left.\mathrm{n}^{\circ} 73,2000\right)$; "Os saberes dos docentes e sua formação" (no 74, 2001); "Políticas educacionais" (no 75, 2001); "Ensaios sobre Pierre Bourdieu" (no 78, 2002); "Diferenças" (no 79, 2002), e "Letramento" (no 81, 2002). No número 77, de 2001, foram introduzidas duas novas seçôes: "Imagens \& palavras" e "Revisão \& síntese".

A Revista é planejada anualmente, com a participação dos Conselhos Editoriais Nacional e Internacional, definindo um número especialtemático, dois números com dossiês e um número plural. Desse modo, Educação \& Sociedade pretende estar cumprindo melhor seu papel na constituição e fortalecimento do campo do conhecimento da educação. Essa política editorial foi implementada no momento em que o CEDES, com o no 57 (especial de 1996) assumiu diretamente a produção de suas publicaçōes, o que implica redução significativa dos custos editoriais da Revista, garantindo-lhe maior autonomia e controle sobre todas as etapas de sua publicação, além de permitir melhorias na qualidade final, em termos gráficos, de layout e de conteúdo. A Revista realizou lançamentos de ediçōes em seminários e mesas redondas, promovidos pelo CEDES, com o apoio de instituiçôes acadêmicas, nacionais e internacionais. A idéia desses lançamentos é uma inovação que permite à Revista alcançar maior visibilidade e conhecimento do seu impacto no campo educacional, além de ser um momento único para o encontro de autores e leitores.

Sua inclusão no Projeto Scielo de revistas eletrônicas (FAPESP) desde o $\mathrm{n}^{\mathrm{o}} 58$, ano de 1997 , na primeira fase de funcionamento pleno do projeto, tornou a Revista acessível à comunidade acadêmica de modo imediato, intensificando o intercâmbio, a colaboração e a polêmica de que depende o avanço do conhecimento. O caráter de "bem público" da Revista foi assim mais uma vez evidenciado.

A internacionalização da Revista tem-se verificado num processo lento, mas cauteloso. O conselho editorial internacional tem sido uma das componentes, na medida em que os seus membros pertencem a diversos países, caso de Espanha, México, França, Alemanha, Itália, Estados Unidos e Portugal.

Para concretizar a idéia de uma edição portuguesa de $E$ $̛ S$, trazida por Almerindo Janela Afonso, em setembro de 2000, a partir do número 
78 (abril de 2002) o comitê editorial integra o nome de José Augusto Pacheco, da Universidade do Minho, cuja ação tem permitido a construção de uma ponte efetiva entre Portugal e Brasil, sobretudo com a participação ativa de docentes e investigadores na revista e ainda com a sua divulgação em Portugal. Deste modo, passam a integrar o conselho editorial internacional, desde o número 79 (agosto de 2002), Almerindo Janela Afonso, Maria de Fátima Sequeira (Universidade do Minho) e João Barroso (Universidade de Lisboa).

O "grupo português" da revista assegura, assim, a divulgação da mesma e prepara-se para tornar efetiva a sua presença em terras lusas a partir do mês de maio, momento em que passará a existir a publicação impressa em Portugal, com a criação de ponto de venda e distribuição e rede de assinantes, através da Livraria Minho, situada em Braga. Para comemorar este acontecimento, realizar-se-á o seminário internacional sobre Políticas Educativas em Portugal e no Brasil - quando será lançada a edição portuguesa a partir da revista no 82 (abril de 2003) -, com apoio tanto da Universidade do Minho, quanto da Universidade Estadual de Campinas, nas instalações da Universidade do Minho. No dia 26 de maio há lugar para a apresentação, na forma de conferência, de quatro artigos da revista escritos por João Barroso, Gaudêncio Frigotto e Maria Giavatta, José Augusto Pacheco e Luiz Antonio Cunha; no segundo dia, ocorre uma mesa-redonda ("A investigação em Portugal e no Brasil pelo prisma das publicações científicas Revista Educação \& Sociedade e Revista Portuguesa de Educação", através dos seus diretores, respectivamente, Ivany Pino e Rui Vieira de Castro, e com a participação de Vera Lúcia Sabongi De Rossi, membro da diretoria do CEDES.

Além do Dossiê já citado, este número apresenta na seção Debates um conjunto de leituras organizado por Jorge Larrosa e Walter Kohan do livro $O$ mestre ignorante, de Jacques Ranciere, desenvolvendo pensamentos sobre a relação educação e política em sua intersecção com igualdade e liberdade.

Com efeito, estão criadas as condições mínimas para a divulgação da edição portuguesa de Educação \& Sociedade em Portugal, sabendo-se que são inúmeras as vantagens que podem advir deste processo, principalmente se considerarmos as potencialidades de uma revista que não pode ficar confinada a um país, mas a uma comunidade tão importante como é o caso da comunidade de língua portuguesa.

Neidson Rodrigues - Com este número de Educação \& Sociedade queremos também homenagear ao colega que acaba de nos deixar fisicamente, mas que permanecerá entre nós como um emérito pensador da 
educação no Brasil. Sua obra escrita (uma dezena de livros, e muitos artigos e capítulos de livros) e sua atuação como professor, pesquisador, dirigente, no campo científico-educacional - UNESP-Assis, UNIMEP e Prefeitura de Piracicaba, Fe/Ufmg e Secretaria de Educação de Minas Gerais, Secretaria da Educação Básica do MEC, revista Educação em Revista e ANPEd, por exemplo - fazem parte daquele patrimônio público nacional do qual todos nos orgulhamos. Vale registrar sua participação no movimento de reorganização do campo educativo nas décadas de 1980 e 1990, em que se destacou sua marca pessoal na série de Conferências Brasileiras de Educação - CBEs e na presidência da ANPEd.

Esta homenagem se dirige finalmente ao autor de nossa revista. A releitura de seu artigo intitulado "Educação: da formação humana à construção do sujeito ético", publicado no Numero Especial (no 76) desta Revista do ano 2001, dedicado ao tema da Ética, Educação e Sociedade: um debate contemporâneo, dá-nos uma boa amostra de seu pensamento crítico, tão necessário em nossos dias. 